only a transient condition. Lastly, the terminal hyperpyrexia, the temperature rising just before death to $107^{\circ} \mathrm{F}$., which occurs not uncommonly in infective conditions, is an interesting point to note.

As regards the relationship between diabetic coma and the presence of the acetone-bodies in the urine, Cammidge ${ }^{1}$ states that "all cases of diabetes are not complicated by acetonæmia, although it is a constantly present menace, since a deficiency in the oxidative process of the body is an essential element of the condition. It is only when this reaches a certain stage that the acetone bodies appear in the urine as a necessary consequence." Further, he states the acetone and aceto-acetic acid, though usually present in the urine when the coma supervenes, are not so abundant as before, but that the amount of beta-oxybutyric acid is generally much increased.

The completed history of the case, with its transient glycosuria, indicates the neurogenous origin of the glycosuria. Regarding this condition, Cammidge ${ }^{2}$ states that "such a transitory glycosuria, apparently of central origin, has been noticed in connexion with lesions of both the central and peripheral nervous system, such as tumours and hæmorrhages at the base of the brain, lesions of the floor of the fourth ventricle, cerebral and spinal meningitis, concnssion of the brain, fracture of the cervical vertebre, tetanus, and sciatica. It has also been met with after epileptic, hysteroepileptic, and apoplectic seizures, in traumatic neuroses, such as those following railway accidents, mental shocks, mental strain, worry, fatigue, and great anxiety."

The practical lesson which this case enforces is the danger of concluding that the presence of sugar in the urine of a comatose individual is necessarily due to diabetes. Further investigations and a critical survey of the history of such a case are essential for the accurate elucflation of the cause of the condition.

We have to thank Captain H. S. Morton, R.A.M.C., for the clinical history of this case, and Surgeon-General J. Dallas Edge, C.B., A.M.S., commanding the Queen Alezandra Military Hospital, for permission to publish it.

\section{THE RECURRENT TYPE OF "TRENCH" FEVER IN MESOPOTAMIA.}

BY O. F. COOMBS, M.D. LOND., M.R.C.P. LoND.,

CAPTAIN, R.A.M.C. (T.F.) ; LATELY ATTACHED TO INDIAN EXPEDITIONARY FORCE " $D$."

THE following case came under my observation recently at Amara, in Mesopotamia.

The patient, an officer aged about 36, was employed at the advanced base and had never been to the fighting line; he had been pulled down a little by one or two attacks of diarrhoea. Towards the end of April he had an attack of fever lasting two or three days, unaccompanied by rigor, and almost certainly not malarial. It seemed to belong to the category of short fevers, of which there were many examples in Amara. These attacks were generally traceable to exposure to the sun, which was beginning to get hot at that time. In this case the fever passed off, leaving the patient perhaps a little more vulnerable to the sun than before, but without definite sequelæ. Soon after a small degree of footdrop developed in the right foot, with some anæsthesia of the dorsum of the foot, but this did not seem to have any direct connexion with the febrile attack which had preceded it.

About the middle of May, after a day of premonitory malaise and depression, the temperature ran up one afternoon to $103^{\circ} \mathrm{F}$. and over. There was some mental excitement, the back and head ached, and the fall of temperature which soon followed was accompanied by a drenching sweat. After a couple of days in bed the patient returned to duty but felt very tired and slack. Just a week after this last febrile attack another one developed. The fever was not so high, but it lasted two or three days. The pains accompanying it in back and limbs were more pronounced. Four similar attacks followed at intervals of exactly six days. Each attack exhibited a little less fever and a little more prostration than those which preceded it. In the later ones the pains were more pronounced, especially in the shins and tarsal bones. These pains were much aggravated by walking, and at night they were sometimes severe enough to

1 Cammidge, P. J.: Glvcosuria and Allied Conditions, p. 214 London: Edward Arnold. 1913.

$$
\text { 2 Loc. cit., p. } 169 .
$$

prevent sleep. Latterly they tended to persist after the febrile bout was over. Possibly there was a fifth attack, but if so the rise of temperature was slight. As it occurred, if at all, during transfer from one hospltal to another, this slight rise may have been overlooked.

In all, therefore, there were six pyrexial bouts. None of them were marked by definite rigor. There was always a day of premonitory discomfort. During the two earlier apyrexial intervals the patient felt comparatively fit, but each returning attack, though in itself less severe, induced a progressive loss of strength and flesh, the latter amounting in all to nearly one quarter of the total body weight. He became very pale and a little short of breath on exertion. The pulse was persistently quickened. The bowels were constipated and the urine normal. The foot-drop already alluded to cleared up slowly with the rest in bed.

The blood was examined several times. No spirilla or other protozoa could be found. Cultures were negative and agglutination results equivocal. There was a mild polynuclear leucocytosis between the fifth and sixth attacks.

Many suggestions were offered as to the diagnosis. $\mathbf{M y}$ own view was that it might be one of the spirillar group of relapsing fevers, but this was negatived by the blood examinations, made by no less an authority than Major F. P. Mackie, I.M.S., whose researches into these diseases are well known. Captain Jamieson, R.A.M.C., recognised the similarity of the symptoms to those which had been described in Flanders under the heading of "trench fever." I was not at that time familiar with this syndrome, but since returning to England and being transferred to France $I$ have seen a number of cases of a recurrent fever which closely resembles the pyrexial illness described above.

Two other cases of a similar fever came under my notice in Mesopotamia, but I have no satisfactory notes of them. In none of the three cases was any treatment effective save evacuation from the country into a cooler climate. This corresponds with general experience of the disease : nothing does much good except rest, plenty of food, and all the other ordinary means of increasing resistance to infection.

The causation is obscure. That the climatic factor may be ruled out is proved by the occurrence of the disease in Mesopotamia, in the Balkans, in the British armies in Flanders and in the French armies in the field, and in the troops on the Volbynian front. So far as the biting insect factor is concerned, Mesopotamia is certainly one with the other war areas; except that there are added various other torments of this description to those which usually adorn the person of the soldier in the field. The whole problem is well worthy of investigation, as the disease may inflict prolonged invalidism on the soldier. Fortunately there do not appear to be any permanent sequelæ.

\section{A PRELIMINARY CONTRIBUTION ON "P.U.O. (TRENCH FEVER)."}

BY F. C. DAVIES, M.B. CAMB., M.R.C.P. LoNd.,

CAPTAIN, R.A.M.C. (T.C.) ; TEMPORARY OFFICER IN CHARGE, MEDICAI. DIVISION, NO. - GENERAL HOSPITAL ; AND

R. P. WELDON, L.R.C.P. \& S. IREL.,

CAPTAIN, R.A.M.C. (T.C.) ; PATHOLOGIS'T, NO. - GENERAT HOSPITAI.

ALMost the only real contribution to our knowledge of this disease, somewhat unfortunately termed "trench fever," which has been published, is contained in the report of the very careful and valuable work carried out under the guidance of Colonel Sir Wilmot Herringham, R.A.M.C., by Captain J. W. McNee, Captain R. J Arundel, Captain Renshaw, and Captain E. H. Brunt. Stated briefly, they have told us that this disease is almost certainly due to an organism which is probably contained in the red corpuscles of the infected persons and that the corpuscular elements of the blood alone are capable of containing and transmitting the disease. This valuable discovery is quite in accordance with what one would expect, judging by the clinical characters so markedly shown in typical cases, and which, in certain respects, are not unlike attacks of malaria. In the main. one would outline these as follows : Sudden onset occasionally with chill. Onset with indefinite but well-marked weakness and malaise, frequently indescribable so far as the patient is concerned, who, when pressed to an extremity in so many instances says, "W Well, my legs would not hold me." 
Pyrexia, severe or slight, irregular, tending to intermit, and with a well-marked suggestion of periodicity of from two or three to five days. Pains, characteristically lumbar, head or legs, all or any, at onset, "shins" later and with extraordinary consistency ; vomiting may occur. In character the pains are best exemplified in these so-called "shin pains" and are of a severe boring character and neuralgic in type, being very frequently associated with marked tenderness of the nerves of the calf, including the external popliteal where it passes round the neck of the fibula, where it is frequently exquisitely tender to pressure. The pains are n't necessarily confined to the shins, but may extend above the knees as far as the thighs, missing the joints.

Certain negative signs and symptoms of great value, when differentiating 1 rom the minor maladies, are freedom from catarrhal conditions of the upper and lower respiratory tracts, absence of dryness or furring of the tongue, even with a temperature of $102^{\circ}$ or $103^{\circ} \mathrm{F}$. The pulse is remarkably stable, and the general feeling of the patients whilst in bed is summed up best in the words they frequently used, "If it were not for this headache I should be alright," or, "If it were not for these pains in my back I should be alright" - a mental attitude which is, in the opinion of the authors unheard of in the typhoid and paratyphoid infections. The spleen is certainly not usually appreciably enlarged either to palpation or percussion. Bowel symptoms we believe not to be characteristic of the condition, though frequently amongst troops, as one would expect, one sees it associated with slight attacks of diarrhoea.

On the course of the disease we cannot speak with confidence, but it would appear that in the majority of cases at least three extcerbation of fever take place extending over an interval of not less than two weeks. The pains are, unquestionably, frequently severe and persistent, though not disabling. The blood shows an absence of any ascertainable growth on ordinary media. A count shows moderate leucocytosis only, with some increase of the large lymphocytes, and an absence of eosinophilia and shows no recognisable hæmatozoa.

One feels it necessary in describing what, to most of us, is a new disease, to emuhasi-e the importance of taking into consideration all the aspects of the case and not to rely upon the presentation of a typical temperature chart or the presence of typical "shin pains" or any other single characteristic, $a$ mistake which is frequently made With this reminder we are convinced that we have in this condirion a disease of undoubted individuality quite distinct from, and in the vast m+jority of cases easily differentiated from, influenza, common cold bilious attack, and myalgia. on the one hand, and the enteric group, malaria, and rheumatic fever on the other, and, in its typical instances, as easily diagnosed as any better known disease, and in its atypical cases well recognised by those who have studied such numbers of cases as the medical division of any large base hospital must provide.

With regard to treitment, it would not appear that any remedies yet tried have materially modified the course of the risease, and this fact combined with the leakage of men which the wide prevalence of the disease appeared to us to cause. led us to a belief in the extreme importance of prophylaxis. Our attention was thus drawn to the mode of transmission. and with the data provided by the workers alrezdy mentioned in our possession, and also the clinical fact that direct transmission in hospital appeared not to exist, it seemed to us that the direct transmission of red corpuscles must be brought ahout by blood-sucking parasites. The wide prevalence of the "louse" as has been so thoroughly investigated by Lance-Sergeant A. D. Peacock, R.A. $\mathrm{U}$ C.. led us to the belief that these pests were the guilty agents.

An experiment was therefore carried out with a view of testing the accuracy of this belief. Some score of lice were collerted and starved in captivity for three days; a number of them died. Two pairs of the survivors were taken and allowed to bite, urder a watch glass, two patients suffering from "trench fever" in an acute stage. After allowing them to feed for about 15 minutes their meal was interrupted, and each of us then allowed a pair to feed upon himself, strictlv confining their sphere of operation by means of a securely fixed watch-glass. The one of us whose duties did not bring him into the wards snbsequently. 27 hours later, allowed his pair to have a further meal on himself. Twelve days later very startling developments took place.
The characteristic symptoms manifested themselves, and he passed through a mont typical attack of the condition of average severity, with the pains and other features all present. It may be further noted that the victim had not at any time been nearer to the front than the base, nor had he been subject to any previous similar condition.

The demonstration of this mode of tranimission appears to be so striking in its success and of such immediate importance that we feel amply justified in giving what is an acalemically incomplete research on the etiology of this important disease. The probability is that $a$ vigorous impulse to the anti-louse campaign may be given

\section{Clinital oftotes:} MEDICAL, SURGICAL, OBSTETRICAL, AND
THERAPEUTICAL.

\section{ACUTE PNEUMONIA WITH HYPERPYREXIA, FOLLOWED BY HEART-BLOCK.}

By J. Porter-Parkinson, M.D. Lond., F.R.O.S. ENG., ERIOR PHYSICLA AT THE LUNDUN TEMPERANCF HOSPITAT AND AT THE QUEKN'B HOSPITAL FOR CHILDREN, HACKNEY-ROAD, E。

ACUTE pneumonia with severe hyperpyrexia is so rare, and recovery from this rarer still, that on that ground alone it would seem desirable to record this case, in which also the fever was followed by a high grade of heart-block.

A van boy, aged 14 years, was admitted into hospital under my care on Nov. 22nd, 1916. He was a healthy looking boy, with a good family and personal bistory. He had been taken ill with a rigor and fever and cough four days previously. On admission the temperature was $104^{\circ} \mathrm{F}$ and $4 . \mathrm{P}$. it had risen to $105^{\circ}$. There were signs of pneumonic consolidation in the whole of the lower lobe of the right lung. The patient's general condition was good. At 7 P.M., however, the temperature, taken in the mouth, registered $110^{\circ}$; it was taken in the rectum by two different thermometers and found to be $110^{\circ}$ each time. On being informed of this by telephone I ordered the immediate use of iced sponging and towels. Towsls wrung out in iced water were placed over the front of the trunk and changed in succession when they became warm, and the limbs were sponged with iced water. In this way the temperature had fallen to $104^{\circ}$ when I arrived at the hospital. The treatment was then stopped. The general condition of the patient was good, he had not been delirious or unconscious. The pulse was 120 , regular and of fair volume, and there was no sign of collapse. I ordered an ounce of brandy in warm milk. The temperature was then taken each half hour and began to rise again, and at 9 P.M. was $103 \cdot 6^{\circ}$; the cold spouging and towelling again reduced it to $103.8^{\circ}$, after which it slowly fell to $101^{\circ}$, but next day it varied between $104^{\circ}$ and $105^{\circ}$, and after this until the crisis on Nov. 27th it showed no tendency to rise to an abnormal height. The course of the illness was uneventful, until on Nov. 30th, two days after the crisis, the pulse had sunk to 44 . When $I$ saw the patient the same day it was beating at that rate at the wrist. The heart's apex was not displaced, and there were no abnormal sounds neard; but I was able to show by a paper lever over the jugular vein that the auricular rate was 88 while the apex beat registered 44. The pulse was of good volume and perfectly regular in rhythm. This passed off after 48 hours, and I regret that I was unable to procure the use of a polygraph early enough to get a permanent record. After this the pulse-rate gradually rose, and was intermittent, at first every three or four beats, but getting less and less so daily until a week later when the rate was about 80 , and only very rarely could an intermittency be felt at the wrist or the apex. The sigus in the lungs cleared up in the usual way, and the only other feature worth noting was that the pulse rate increased considerably when the patient was first allowed out of bed, so that his convalescence wag retarded in this respect for about a fortnight.

A temperatu e of over $106^{\circ} \mathrm{F}$. is exceedingly rare in acute lobar pneumonia but commoner in broncho-pneumonia. The percentage in the former disease is said to be 04 , and with only one or two exceptions seems to have been fatal in all the recorded cases. The fact of recovery afrer the temperature twice reached an extraordinary height seems, as far as I can make out from the literature, to be almost unique.

It was found that whenever iced towels were renewed over the præcordial region the pulse became markedly more feeble. 